\title{
AKTÜEL OLAYLAR
}

\section{«MUKAYESELI DEVLET IDARESI VE TÜRKIYE" ÜZERINE BIR SEMINER}

Prof. Bahri SAVCI

I

\section{G I R I S}

Princeton Üniversitesinin doçentlerinden Dankwart A. Rustow, Türkiye'de bir ilmî tetkik yapmak üzere bulunduğu 1958 - 59 ders yılında, kendisi ile İdarî İlimler Enstitüsï çerçevesi içinde temaslarımız olmuştur.

D. A. Rustow, lise ve üniversite tahsilini Türkiye'ide yapmış olan genç bir ilim adamıdır. Amerika'da, bilhassa Princeton Üniversitesinde kendisi gibi genç ilim adamları ile birlikte, mukayeseli devlet idaresi alanında incelemeler yapmaktadır .Mensup olduğu bu genç ilim kuşağı, bilhassa, Asya - Afrika devletleri üzeninde dummaktadırlar. Türkiye'deki sosyal ve siyasal oluşu yakından izliyen bu ilim adamının, Amerika'daki mukayeseli devlet araştırmaları alanına pek değerli katgılar getirdiği ve getireceği bir gerçektir. Kendisinin, Fakülttemiz çevresindeki çalışmaları sırasında; modern mukayeseli devlet idanesi tetkikleri muvacehesinde Türkiye'nin durumunu, işgal ettiği yeri de işaret eden bir seminer yapma kararına varıldı. Sayın Doçent, bu seminerin konusunu açmağ1 ve tartışmada ortaya çıkan sorulara cevap vermeği üzerine aldılar. Aşağıdaki II numaralı serlevhalar altında göziiken izahatı - bu metinde gösterilenden pek az bir farkla - yaptılar. Bundan sonra bir genel tartışma açıldı. Bu tartışmada seminerin 12 üyesi, bir veya müteaddit defa söz aldı, fikrini açıkladı.

Șimdi okurlarımıza, bu girişten sonra, bu seminerin esasını teçkil eden Dr. Rustow'un izahatını itiva heden metni sunuyoruz. Bundan sonra III numaralı serlevha altında da, yapılan tartışmada ortaya çkan görüșleri işaret edeceğiz. Bu suretle bu II ve III 
ünoü serlevhallar altında gösterilen fikirlerin üzeninde okurların ve bütün ilgililerin tekrar düşünmeleri sağlanmış olacaktır. Seminerden bu yana üç yıl geọmiş olmasına rağmen, bu fikirlerin, bir seminerin dar çerçevesinde kalmamasını istedik, bunda büyüik bir yarar gördük. Bu seminerde, Türkiye'de ordu meselesini ele alan fikirleri, ariada yaıplmış olan 27 Mayıs 1960 İhtilâlinin bizi çıkardığı yüiksek prespektifden bir kere daha düşünmede çok yarar vardir. 


\title{
II
}

\section{KONUYU ACIKLAYAN METIN "MUKAYESELİ DEVLET IDARESİ VE TÜRKIYE»}

\author{
Yazan : \\ Dr. Dankwart A. RUSTOW \\ Associate Professor of Politics \\ Princeton University
}

Mukayeseli devlet idaresi (yahut İngilizce tabiriyle, comparative government) bir ilim mevzuu olarak uzun ve zengin bir an'aneye sahiptir. Menșelerini Aristo'nun, İbni Haldun'un, Machiavelli'nin ve Montesquie'nün yazılarında görebiliriz. Modern mânada ise mukayeseli devlet idaresi mevzuunun yetmiş senelik kadar bir mazisi vardır ki, bu müddet zarfında mevzuun dört ayrı safhadan geçip geliștiği söylenebilir. Her safha da, hem mevzuun tayini ve tahdidi ve hem de metod bakımından ayrı ayrı bazı vasıfları haizdir.

Ondokuzuncu asrın sonlarına doğru, mukayeseli devlet idaresi anayasa tetkiklerine münhasırdı ve bu tetkiklere de tarihî ve bilhassa hukukî metod hâkim idi. Bu vaziyeti, Columbia Üniversitesi profesörlerinden J. W. Burgess'in 1896 senesinde neşrettiği "Political Science and Companative Constitutional Law» (yâni, "Siyasî İlim ve Mukayeseli Teșkilât Hukuku») başlıkh kitabın adı gayet giuzel ifade etmektedir.

Gelişmenin ikinci safhasında da hukukî metodun yerine daha ziyade empirique metodun tatbik edildiğini görüyoruz. Yani comparative government mütehassısları, yalnız anayasaların hukukî kaidelerini değil, aynı zamanda devletin başlıca müesseselerinin fiiliyattaki çalışmalarını da incelemeğe başlamaktadır. Ve devletin idarî ve teşrî̀ organlarının yanında bilhassa siyasî partiler mühim bir araștırma mevzuu teşkil etmektedir.

Üçüncii safha, Birinci ve İkinci Dünya Harpleri arasındaki devreye rastlamaktadır ve bu sáfhada da efkârı umumiye, propa- 
ganda, ve (kamu oyu) baskı grupları "pressure groups» gibi yeni yeni mevzular ilmî alâkayı çekmektedir.

Gelişmenin dördüincü safhası ise, şu son beş on sene içinde açılmıştır. Başlıca vasfı da, Avrupa ve Şimalî Amerika memleketlerinin yanında Asya, Orta Șark ve Afrika memleketlerinin dahi ilmî tetkik ve çalışmalarda eskisine nisbetle çok daha büyük ve mühim bir konu olma rolü oynadıklarıdır.

Mukayeseli devlet idaresi mefhumunun bu üç şeyrek asır içinde ne derece esaslı şekilde değiştiğini takdir etmek için, Woodrow Wilson'un 1889 senesinde intișar eden Devlet (The State) adlı kitabına bir göz atmak kâfidir zannederim. Meselâ müellif, Fransa, Ingiltere, Almanya gibi memleketlere birer bahis hasrettiği halds, hem Avusturya-Macaristan'1 ve hem de İsveç-Norveç Birliğini "çifte monarşiler» başlıklı tek bir bahiste ele almaktadır. Wilson bu arada, Avusturya-Macaristan'in tek bir anayasası ve tek bir kabinesi olduğunu, ve öte taraftan İsveç-Norveç Birliğinin tek bir kral altında ayrı ayrı anayasa ve kabinelerle idare edildiğini görerek, ikisinden Avusturya İmparatorluğunun çok daha mütecanis ve çok daha yeknasak olduğunu iddia etmektedir. İsveç Norveç Birliğinin 1905 senesinde (yani Habsburg İmparatorluğunun inkırazınidan onüiç sene evvel) infisah etmesi, belki, Wilson'un bu hükmünün haklı olduğunu gösterdiği düșünülebilir. Fakat yedi veya sekiz ayrı ayrı milleti ihtiva eden Avusturya İmparatorluğunu mütecanis görüp de, hemen hemen aynı dili konuşan ve aynı kültürel ananelere sahip olan İsveç - Norveç'i gayri müitecanis addetmek, bugünküi düşüncemize göre ne kadar dar bir göriişün, ne kadar sun'î ve şeklî bir tasnifin mahsulü olduğu herhalde âşikârdır.

Mevzuumuzun inkișafında ve bir safhasından diğer safhasına doğru tekâmüliünde tarihî hâdiselerin ehemmiyetli bir tesiri olduğu muhakkaktır. Aynı zamanda mevzuun empirique çerçevesi gittikçe genişlemiştir; ve komșu içtimaî ilimlerle yeni yeni münasebetler hasıl olmuștur. Meselâ, İngiltere'de 1880 senelerinde Joseph Chamberlain'in idaresinde meşhur Birmingham Caucus teşkilâtının kurulmasını modern mânada kitle partilerinin menșei olarak kabul edersek, bu hâdisenin yirmi otuz sene sonra Ostrogorski, Lowell, Bryce ve Michels gibi yazarların partileri sistemli bir șekilde incelemelerine ve bu suretle mukayeseli devlet idaresinin ikinci safhaya geçmesine meydan verdiğini görürüz. Birinci Cihan Harbinden sonra Avrupa'daki diktatörlüiklerin zuhuru ile demokratik memleketlerde sendika ve sair iktisadî teşkilâtların büyük öl- 
çüde siyasî faaliyete geçmeleri, propaganda ve "pressure groups» gibi konuların mukayeseli devlet idaresi mevzuu çerçevesine girmelerine sebep olup inkişafın üçüncü safhasını açmıştır. Ondokuzuncu asrın sonlarında hukukî metod ve hukukî görïș ve tasnifler mevzuumuza hâkim olduğu halde, bu sefer içtimaiyat ve psikoloji gibi komşu disiplinlerle daha yakından temasa başlamıştır. İçine daha henüz girdiğimiz dördüincü safha - yâni mukayeseli devlet idaresinin şümulüne Asya, Orta Şark ve Afrika memleketlerinin de girmeleri - sömüngelerin İkinci Dünya Harbi akabindeki istiklâl hareketlerinin ve bu arada soğuk harp sahnesinin bu memleketlere intikalinin tabiî bir mahsulü olmuştur. Asya ve Afrika'da istiklâllerine yeni kavușmuş memleketlerin içinde bulunduklanı iktisadî ve kültürel inkılâbı nazarı itibara alınsak, siyłasi ilmin bir tanaftan iktisatla, öte taraftan antropoloji veya etnografi ile daha yakın temaslana geçtiğini gayet mantıkî addedebiliriz.

$\mathrm{Bu}$ son gelișmenin metod ve epistemoloji bakımından fevkalâde ehemmiyetini ayrıca belirtmek isterim. Denebilir ki tabî̂ ilimlerde lâboratuvar tecrübeleri ne rol oynarlarsa, siyasî ilimlerde mukayese usulï de o rolii oynar. Bu bakımdan eskiden sırf Avrupa ve Şimalî Amerikı memleketlerini araştıran eski mukayeseli devlet idaresi mütehassislarını, tabiat kanunlarını, altı, yedi veya on lâboratuvar tecrübesinden istidlâl etmeğe kalkışan birer fizikçiye yahut kimyagere benzetebiliriz. Halbuki bilindiği gibi, fizik ve kimyada yedi sekiz tecrübe ile iktifa edilmez, yüzlerce ve hattâ binierce tecriibeye dayanılır. Dünyada halihazırda seksen küsur millet mevcut olduğuna göre, ilim ismine gerçekten lâyı olan bir siyasî ilim, bütün bu seksen milleti içine alması zarurîdir. Bu hedefe doğru ne kadar hızlı yüründüğünü takdir etmek için, Amerika'da mevzuumuzun bașlıca mecmuası olan American Political Science Review'nun fihristine bir göz atmak yeter. Eskiden sadece Amerikan Anayasası, devlet nazariyelerinin tarihçesi, ve Avrupa memleketlerinin siyaseti gibi mevzular üzerinde makaleler ihtiva eden bu meamua, son senelerde faaliyetini büyük ölçüde Asya, Afrika ve Orta Doğu memleketleri üzerinde teksif etmiștir. İște bu suretle, mevzuunu teşkil eden bütün empirik doneleri nazarı itibara alan, hakikî mânada cihanşümul bir siyasî ilim gayesine doğru - ilk defa olarak - gitmekteyiz denilebilir.

Fakat diyeceksiniz ki daha beș on sene evvel ethnocentrism'leriyle (yâni kendi kültürel görüșlerine fazlasıyla bağlı olmalarıyla) maruf olan comparative government mütehassısları, nasıl olur da, birdenbire, eski prejujélerini kenara atıp böyle cihanşümul bir il- 
mi vücuda getirebilirler? Dikkat ederseniz gayeye varmışız demiyorum; ancak istikamet ve hedefin ilk idefa olarak belirdiğini iddia ediyorum. Gayeye yaklaşınca birçok engelleri aşmak mecburiyetinde olduğumuz șüphesizdir.

Filhakika, Asya veya Afrika'nın yeni memleketlerinde siyasî araştırmalanda bulunan âlimler, batı memleketlerinde hiç rastlamadıkları bazı güçlüklerle karşı karşıyadır. Meselâ eskiden Ingilizce, Fransızca ve Almanca bilmekle iktifa edilebildiği halde, bugün Arapça, Japonoa, Malayca gibi ögrrenilmesi hiç te kolay olmıyan lisanları okumak mecburiyeti hasıl olabilir. Lisan öğrenip de Endionezya, Fas, Afganistan gibi memleketlende araştırmalarına bașlıyan mütehassıs, istatistiklerin kifayetsizliğinden, hattâ nüfus sayımlarının hiç yapılmamıș olmasından, gazetelerin havadis yerine sahiplerinin indî kanaatlariyle dolu olduğundan, bașkentteki siyaset adamlarının kendi taşralarını asla bilmeyip neticede iştirak ettikleri siyasî hareketlerin hakiki mahiyetini idrâk ve izahtan âciz kaldıklarmdan ve daha birçok maddî ve mânevi müşküllenden şikâyet edeceği muhtemeldir. Fakat işin en müşkül tarafı, bu kadar zorlukla ortaya çıkarılan olaylara uyacak faraziyeler ve nazariyeler keşfetmektir. Meselâ Avrupa siyasî sistemleri incelenirken, kültürel muhit, iktisadî seviye gibi hususlar birer sabit, done olarak kabul edilebilirdi; devletlerin hüviyeti ve siyasette rolleri olan iktisadî ve içtimaî tabakaların vasıf ve hedefleri, aşağı yukarı malûmdu. Asya ve Afrika'nın memleketlerinde ise hem kültürel muhit ve hem de iktisadî seviye çok hizla değişmektedir. Ve bu iktisadî ve kültürel değișmeler siyasete derinden tesir ettikleri gibi aynı zamanda siyasî tartışmaların da başlıca mevzuunu teșkil etmektedirler. Birçok memleketlerde iktisadî ve içtịmaî sınuflar tam mânada taazzuv etmemiştir, taazzuv etmişse gayelerini vüzuhla belirtmemiștir. Pakistan, Ürdün ve birçok diğer yeni memleketlerde ise devletin ne hüviyeti, ne sinirları, ne nüfusu, ve ne de bekasi bir done olarak kabul edilebilir. Demek oluyor ki siyaset nazariyelerinde eskiden sabit olarak ele alınan birçok hususlar birer variyable haline gelimiştir ve neticede de tetkikatımız o derecede güiçleşmiștir. Nihayet Avrupa ve Șimalî Amerika memleketleri tarihî ve iktisadî ve siyasî mahiyetlerinde birbirine az çok benzedikleri halde, hem Ghana'yı ve hem de Japonya'yı, hem Hindistan'i ve ham de Libya'yı içine alacalk nazariyeler keşfetmek hiç de kolay olmayacaktır.

Bu vaziyet karşısında ilim adamının ilk vazifesi, Asya ve Afrika'nin yeni memleketleri arasındaki benzerlikleri tesbit etmek ol- 
sa gerek. Ve nitekim bu memleketlerin bazı müssterek vasıfları olduğu muhiakkaktır. Iki sene evvel neșrettiğim bir makalede bu müşterek vasıfları şu liste ile tesbit etmeğe çalıştım: (*)

1 - İktisadiyatta hızlı gelișmek arzusu

2 - Garblılaşma hareketi neticesinde hem batı kültürüne ve hem de memleketlerin kendi tarih ve kültürlerine karşı bir «ambivalence» (yâni hem red hem kabul) hissinin uyanmasi.

3 - İçtimaî bünyenin hızla değişmesi ve bu arada içtimaî grupların karşılıklı bağlılıklarının gittikçe artması.

4 - Siyasî tatbilkatın anayasa hükümlerine ve memleketçe kabul edilen siyasî ideallere uymaması.

5 - Milliyetçilik hissinin yeni olup neticede hem istikrarsız ve hem tecaviuzkâr olması.

6 - Parti gibi siyasî teşkilâtların tam olarak taazzuv etmemiş olması.

7 - Devletin idare sahasının çabukg̣a genişlemesiyle idarî tecrübesizliğin hükü̈m sürmesi.

8 - Beynelmilel siyasette tek başına müdafaa imkânlarının mahdut olmasi.

9 - Yeni milletlere önderlik ve rehberlik edebilecek büyük devlet adamlarına ihtiyaç hissedilmesi,

Siraladığım bu vasıfların Asya ve Afrika'nın her memleketinde aynı șekil ve derecede belirmeyecekleri tabiîdir. Maamafih bu veya buna benzer bir tasnifin yeni ilmî bir nazariyeye doğru ilk bir adım teșkil ettiğine kaniyim.

Bu mevzuu birakmadan bugünkü ilmî vaziyetin başka bir cihetine işaret etmek isterim. Mukayeseli devlet idaresinin bundan önceki, ve bilhassa ikinci ve üçüncü safhasında, tetkik mevzuu birkaç nesilden veya asırdanberi mevcut olan siyasî teşekküller olduğuna göre, devletlerin nasıl vücuda gelip nasıl inkıraz ettiği

(*) Bak: Dankwart A. Rustow, «New Horizons for Comparative Politics,” World Politics, vol. 9, no. 4 (July 1957), pp. 530-549, bilhassa pp. 537-544. Arkadaşım Lucian W. Pye ayni şekilde 17 noktalık bir liste tesbit etmiștir: "The Non. Western Poltical Process,") The Journal of Politics, vol. 20, no. 3 (August 1958), pp. $468-486$. 
incelenmezdi. Ileri sürülen nazariyeler statik mahiyette idi. Bugün müstemleke imparatorluklarının inkırazları ve arkalarından yeni yeni devletlerin teessüisü mevzuumuzun pek mühim bir kısmını teşkil ettiğine, devletlerin doğumunu ve ölümünï sistemli bir şekilde inceleyip izaha çalışmak mecburiyetindeyiz. Ve bu arada onsekizinci asrın içtimaî mukavele nazariyecileri gibi dedüiktif değil endüktif ve empirik bir usul takip etmemiz tabiîdir.

Mukayeseli devlet idaresinin gözden geçirdiğimiz bu inkişafı ile Türkiyenin ne alâkası vardır?

Türkiye'nin hem Avrupa memleketlerine ve hem de Yakın Şark ve Asya memleketlerine mühim bazı benzerlikleri vardır. Bu bakımdan Türkiye, siyasî ilmin ötedenberi araştırdığı batı memleketleri ile daha henüz incelemeğe başladığımız şark memleketleri arasında pek mühim ve nev'i şahsına müinhasır bir bağ teşkil ettiğine kaniim.

Demin sıraladiğım vasıflar ele alınınsa, bunlardan bazılarının Türkiye'de de mevcut olduğu, bazılarının hiç olmadiğı göze çarpar.

Meselâ Atatürk inkılâbıyla kültür değişmeleri, ve bu son on sene içinde de iktisadî gelişme meselesi Türk siyasetinin ön plânına gelmiștir. Milliyetçilik hissinin daha nisbeten yeni olduğunu Jön Türk hareketinin, İkinci Meşrutiyetin, ve hattâ Millî Müicadelenin tarihi gösterir. Nihayet, anayasanın esaslı hükümlerinin siyasi hayatta nasıl tatbik edileceği hususunda Türk vatandaşları arasında tam bir hemfikirlik mevcut olmadiğına ondört seneden beri devam eden siyasî tartışmalar delildir. $\mathrm{Bu}$ tantışmalar yalnız teferruata değil, aynı zamanda rejimin esas meselelerine taallûk etmektedir

Öte taraftan, Türkiye ile diğer Asya ve Șark memleketleri arasında pek mühim fark ve hattâ tezadlar mevcut olduğu âşikârdır. Garblilașma hareketi Türkiye'de șu son on veya yirmi sene içinde başlamış değildir; tâ İbrahim Müteferrika, Selim III, Mahmut II, Reșid ve Mithat Paşalar zamanlarından beri sürekli ve kesif bir şekilde devam edegelmiştir. Bütün Afrika ve ekseri Asya memleketlerinin hilâfına, Türk milleti, tarihinin en gergin ve kıranlık zamanlarında bile istiklâlini müdafaa ve muhafaza etmiş, hiçbir zaman müstemleke vaziyetine düşmemiştir. Bu itibarla Türkiye'deki bir iki asır boyunca devam eden garblılașma hareketi yabancı hükümetler tarafından zorla kabul ettirilmemiștir. Türk devlet 
edebiyat ve kültür adamlarının kendi ihtiyarlariyle husule gelmiştir.

Milliyetçilik hissi Türkiye'de nisbeten yeni olduğu halde, millî misakla tayin edilen ve millî mücadelede dünyaya tanittırılan hudutlar içinde sağlam ve müstakar bir şekilde inkişaf etmiştir. $\mathrm{Bu}$ itibarla Hindistan, Endonezya, Pakistan ve Arap memleketlerinin siryasetini karıştıran çeşitli millî tesanüd, millî birlik, ve millî hudut meseleleri, Türkiye'de ötedenberi halledilmiş bulunuyor. Türk ordu zabitlerinin milliyetçilik şuurunun gelişmesinde ve millî Türk devletinin kurulmasında büyüik ve hattâ esaslı bir rolleri olduğu muhakkaktır. Fakat bu vaziyet, Arap, Asya ve Cemubî Amerika memleketlerinde ve hattâ Osmanlı Imparatorluğunun son senclerinde olduğu gibi ondunun siyasete sik sik müdahale etmesine meydan vermemiștir; bilâkis, tâ millî hüikümetin kuruluş̧undan beri ondu işleri siyaset işlerinden ayrı tutulmuștur.

Âmme fonksiyonlarının çabukça genişlemesi, diğer memleketlerde olduğu gibi Türkiye için de varittir. Yalnız bu âmme vazifelerinin ifasında diğer birçok memleketlerde aslâ mévcut olmayan tecrübeli bir memur kadrosu Türkiye'de ondokuzuncu asrın sonlarındamberi bulunmuștur. Bu kadronun yetişmesinde yakında yüzüncü yıldönüimii kutlanacak olan bu eski Müllkiye, yeni Siyasal Bilgiler Fakültesinin ne büyük hizmeti olduğunu hepimiz biliriz.

Tünkiye'nin en mühim hususiyeti, tarihinin en gergin zamanında Atatürk şahsında yeni bir devleti uzak görüş ve fevkalâde bașarı ile yeni temeller üzerinde tesis eden büyüik bir devlet adaminin mevcudiyetinde görebiliriz.

Hulâsa, dünyanın her tarafında ön plâna geçmiş olan garblılaşma, iktisadî gelișme, yeni devlet kurmak, milliyetçilik şuurunu uyandırp ona istikrar ve istikamet vermek, ve siyasî hayatı vatandaşların anayasa ideallerine tetabuk ettirmek gibi siyasî problemler Türkiye için de varittir. Ancak diğer memleketlerde halledilemiyen bu problemlerin çoğu Türkiye'de halledilmiștir. İşte bunun içindir ki mukayeseli devlet idaresi mevzuunun bütün dünyaya teşmil edildiği bu șnalarda Türkiye Cumhuriyetinin siyasî tarihi ve sivasî sistemi üzerinde yapılan ve yapılacak etüdlerin fevkalâde bir ehemmiyeti haiz olduğunu iddia etmekteyim. Bu gibi etuidlerin lâyıkiyle yapılmaları için, yabancılar tarafından değil, siyasî ilimleri meslek edinmiş Türk vatandışlar tarafından yapılması lâzımdir. 


\section{B I B L I Y O G R A F Y A}

Almond, Gabriel, A., "Comparative Political Systems," Journal of Politics, vol. 18 (August 1956), pp. 391.409

Coleman, James S. «The Problem of Political Integration in Emergent Africa," Western Political Quarterly, vol. 7 (1955), pp. 44-57

Deutsch, Karl W., Nationalism and Social Communication, New York 1953

Emerson, Rupert, «Paradoxes of Asian Nationalism,» Far Eastern Quarterly, vol. 18 (1954), pp. 131-142

Emerson, Rupert, Representative Government in Southeast Asia, Cambridge (Mass.) 1955

Finer, Herman, Theory and Practice of Modern Government, revised edition, New York 1949

Fortes, Meyer, and E.E. Evans-Pritchard, African Political Systems, London 1940.

Friedrich, Carl J., Constitutional Government and Democracy, revised edition, Boston 1950

von Grunebaum, Gustave E., "Problems of Muslim Nationalism,» in Islam and the West, edited by Richard N. Frye,' 's-Gravenhage 1957, pp. 7.29

Kahin, George McT., editor, Major Governments of Asia, Ithaca (New York) 1958

Kahin, George McT., Guy J. Pauker, and Lucian W. Pye, "Comparative Politics in Western Countries, "American Political Science Review, vol. 49 (December 1955), pp. 1022-1041

Macridis, Roy_C., The Study of Comparative Government, New York 1955

Neumann, Sigmund, “Comparative Polities: A Half-Century Appraisal,» Journal of Politics, vol. 19 (1957), pp. 269-290.

Neumann, Sigmund, editor, Modern Political Parties: The Comparative Approach, Chicago 1956

Pye, Lucian W., “The Non-Western Political Process,» Journal of Politics, vol. 20 (1958), pp. $468-486$

Rustow, Dankwart A., "Foreign Policy of the Turkish Republic," in Foreign Policy in World Politics, vol. 9 (1957), pp. 530-549

Rustow, Dankwart A., “Politics and Islam in Turkey 1920-1955, in Islam and the West edited by Richard N. Frye, 's-Gravenhage 1957, pp. 69-107

Rustow, Dankwart A., Politics and Westernization in the Near East, Princeton: Center of International Studies 1956

Rustow, Dankwart A. "The Army and the Founding of the Turkish Republic, World Politics, vol. 11, no. 4 (July 1959)

Tunaya, Tark Zafer, Türkiyede Siyasî Partiler, Istanbul, 1952 


\section{III}

\section{SEMINERDE ORTAYA ÇIKAN GÖRÜȘLER, FIKİRLER}

Yukarıda gösterilen metinden, hemen hemen, ancak birkaç kelime ile farklı olarak yapılmış açıklamadan sonra, hatipler, konunun türlü yönleri üzerindeki görüșlerini açıkladılar. Bunların bir kısfına Doçent Dr. D: A. Rustow kendi cevabî mütalâalarını ekledi. Büitün konușmaların ifade etmeğe çalıştığı hususları, şöylece göstermak, bize mümküin görüldii :

1 - Yukarıda metni de verilmiş olan izahat, önce bir tahlilden ibarettir; sonra da, bu izahat, gelișmiş bir mukayese alanı içinde Türkiye'nin yerini tayin etmeğe uğraşmaktadır. Binaenaleyh, hem bir ilim dalı olan mukayeseli devlet idaresinin gelișmelerini incelemeği, hem de, bu arada Türkiye'yi incelemeği dikkat nazarina almak gerekir. Mukayeseli devlet tetkikleri, muayyen bir rejimin - meselâ demokrasinin - tetkiki değildir; daha çok, Asya Afrika memleketlerindeki "devlet» i incelemek, enteresandir. Mukayeseli devlelt idaresi tetkikerinin asıl amacı; değişkenleri pek farkli olan memleketlerin müesseselerini inceliyerek, bu hususta, hepsine kabili tatbik bir kanun, bir nazariye bulmak, hic olmazsa genel temayülleri bulmaktır. Seminerin bazı uzuvları; lâboratuvar denemesi olmayan bu bilim alanında, bilimin, bazı temayiilleri bulma güçlügüunüi işaret etmişlerdir; bu alanda, «kanum» lara varmanın tehlikesini göstermilșerdir. Fakat, siyasi ilimlerde mukayese metodumun, lâboratuvar yerini tutacağı ve bu mukayese metodu ile, siyasi ilimler alianında da genel temayüllere ve kanunlara gitmenin mümkün olabileceği de ileri sürmüsştür. Fakat, esas gayenin zatien kanunlar aramak olmadı̆̆ı, "trend» leri aramak olduğu tesbit edilmiştir. Öyle ki, bu amaca varmak için, mukayeseli devlet tetkikleri; bir taraftan birkaç önemli devlet tipini ele alıp, onları esas alıp incelemesine devam ederken, öte yandan da, devlet vasfını haiz olan - ve bugün sayıları $80 \mathrm{i}$ bulan - bütün teşekkülleri ele almak zorunda kalacaktır. Bu yol ile, önce, belki, bazı pek umumi jeneralizasyonlara varılacaktır. Fiakat, sonraları, birtakım teferruat üzerinde çalıșmadan gelen bir idrâk ile, bu jeneralizasyonlarda hatalar ortaya çıkıcaktır. Bu da, ilmî bir çalışmadan ibarettir. Ilimde önce, bilinen teferuatlar ele alınıp, ona uyan jeneralizasyonlar yapılır. Sonra, teferruatlar ortaya çıtıkça, jeneralizasyondaki yanlıșhikların payı meydana çıkarılır ve gereken doğrulamalar yapılır. Bu davranıs yoluyla, bu metod ile, umumi kanunlara ulaşılıp ulaşılamıyacağı konusunda, bir mutedil davranmanın 
gerekeceği kanaatine varılımıştır. İlim, muhiti anlama arzusundan doğmaktadr. İlim ve onun mensubu, bu hususta elinden geldiği kadar çalıșır. Belki, hiçbir zamań tam kemâle varıp küllî ve yegâne kanuna ulaşamaz. Hele, zamanımızda fizikî ilimlende bile eski muayyineyetçiliğin terkedildiği, esas itibariyle trendleri işaret etmeğe doğru gidildiği gözönünde tutulursa, bütün içtimaî ilimlerde de, muhakkak kanunlar aramayı, biraz mutedil telâkki etmeik daha münasip olur.

2 - Muasır mukayeseli devlet tetkikleri ile ulaşılabilecek bu trendleri gösterme çerçevesinde kalırsak, şu hususlan tesbit imkânina kavușuruz:

Batı memleketleri ile Asya - Afrika memleketlerinin gelişmeleri arasında, muhakkak ki bazı noktalarda bir benzerlik vardır. Önce: meselâ, milliyetçilik şuuru, her iki cephedeki memleketlerde de uyanmıștır. Buna kanşılık, iktisadî münasebetler alanında, bu iki grup memlekette büyüik farklılıklar hasıl olmuștur. $\mathrm{Bu}$ sebeple, Avrupa'nın bugüinkü ileri sanayileşmiş devresinin mûtalarını, Asya memleketleri üzerindeki bir mütalâada esas almak pek mümkün görülemez. Meselâ, Avrupa'nın sanayileşmesinin ilk devresini ele alıp, buradaki mûtaları, șimdi o devreye tekabül ediyor kanaati ile, Asya memleketlerine tatbik etmeğe de imkân yoktur. Çünkü, hem Avrupa'nın bugünkü ileri sanayileșmiș devresi ile Asya memleketlerinin iktisadî durumu arasında, hem de, Avrupa'nın sanayileşmesinin ilk devresi ile, Asya memleketlerinin bugnüikü sanayileșmeğe başlama devresi arasında farklılıklar vardır: Avrupa' da, sanayi hareketi bașlarken, kendisine üstün bir başka sanayileșme yoktu. Ayrica, bu sanayileșmede vâki olan gelişmenin hedefi de belli değildi. İște bu ayrilıklar, her yere şâmil genel trendleri bulmakta bir güçlïk yaratıyor. Bununla beraber; mukayeseli tetkiklerde tarihî açıya dikkat ederek bu güçlükleri kısmen yenmek mümkündür. Bu genel trendleri kavramada, amprik noktai nazar, sadece, bugün mevcut 80 küisur memleketi incelemekle yetinmemek gerektiğini ifade eder; bu 80 küsur memleketin yanında, geçmişteki memleketleri de, tarih kanalı ile, tetkik alanı içine almalıdır. Mukayesenin, bir lâboratuvar deneyi mahiyetinde yarar yaratabilmesi için, bu deney sayısını arttırmak mânasında olmak üzere tarihteki geçmiș memleketleri veya geçmiş safhaları da mukayese alanı içine almak gerekir.

Bir diğer nokta da șudur: Değişkenleri - variables - çok olan memleketlerin müesseselerindeki trendleri bulmadia şu mesele de önemlidir: Batıda bir demokrasi vardır. Bunun, orada doğması- 
nın kendisine mahsus doğuş sebepleri de var. Şimdi, demokrasiyi bir vâkıa olarak kabul etmiş olan, fakat batıya mensup olmıyan diğer topluluklara bakalım. Buralarda, demokrasiyi doğuran sebepler, şartlar mevcut değil. Onlar, bu şartları yaşamamışlardır. Ama, yaşamış̧̧asına - sanki o şartlar mevcut olmuşlar gibi - neticelerini, tesirlerini hissediyorlar ve bir demokrasiye geçiş yaptyorlar. İște, mukayeseli devlet idaresi, şartları demokrasiye elverișli batı memleketleri ile bu şartlardan uzak kaldığı halde demokrasiye geçiş yapan memleketlerin demokrasi konusundaki trend'ini bulacaktır. Bunu da şöyle yapacaktır: Demokrasinin asgarî müşterekleri vardır, müitearifesinden kalkılarak, bu asgarî müştereki teşkil eden unsurları arayıp bulacaktır. Demokrasinin bu asgarî müştereklerini sabitleștiren unsurları kuvvetle ihtiva eden ülkelerde, demokrasinin âkibeti münakaşa edilmez bir gerçek halinde gözüküiyor. Fakat ilmî açıdan, demokrasi, kendisine mahsus ön şartları bulunmayan ülkelerde de muhakkak varılması zaruri bir sonuç değildir. Asgarî müişterekleri olan ve bunları geliştiren Asya - Afrika memleketlerinde de demokrasiye, ileride, belki vartlır, belki varılmaz. Şimdilik yapılabilecek olan; asgarî şartları, asgarî müșterekleri bulmak; bunlarla demokrasiye nasıl gidildiğini tesbit etmek; bu asgarî şartlanda, bu asgarî müștereklerde bir derece mevcut olan iştirâke rağmen, bazı esash farklar da varsa, onları tesbit etmektir. Meselâ, Türkiye'de, demokrasinin bazı ön-şartları bulunmadığı halde, yine de demokrasiyi mümkün kılar gözüken bazı müşterek şartları vardır. Bir gelişmenin mümkün olabilmesi için, meselâ, bir demokrasi gelişmesinin mümkün olabilmesi için, ön-şartların aynen mevcut olmasını aramaktan, istemekten vazgeçebiliriz. Demokrasinin olması için, muhakkak, Ingiltere'deki ön-şartlar cümlesinden olan tarihî seyrin geçirilmesi gerekir demek, ilmen doğru ve mümkün değildir. Asgarî müștereklerdeki benzerliğe rağmen, bazı esaslı farkların mevcut olmayışı da, gelişmeyi dundurur, demek, yine doğru ve mümkün değildir. Meselâ, Türkiye ile Batı arasında, bir demokratik nizamda söz konusu olabilecek olan lâiklik mefhumunu ele alalım. Bu konuda Türkiye ve Batı arasında bir farklı telâkki tarzı vardır. Batıda lâiklik, din müessesesinin, devlet hayatı içinde bir farklılık isteyip, istiyememesidir. Orada, bir din mektebi talebeleri için bir otobüs servisi yapılabilir mi, yapılamaz mi gibi bir mesele ve müessese konuşulur lâiklik konusunda... Türkiye'de ise, lâiklik, temeli; lâik olduğu halde, devletin -lâik devletin- din ile olan bütün alâkalarının kesilmesine kadar giden bir tatbikat şekline varamıyor: Din, bütçesini devletten almakta devam ediyor; lâik devlet. 
din müiessesesini, dinî müiesseseleri kontrolü altında tutuyor. Yâni, lâik temele rağmen, bir devlet-din alâkası mevcut olmakta devam ediyor. Çünkü, bu alâka, kesin olarak kesilse idi, bu sefer, irtica, devlete kadar tesir edecekti. Demek ki, Türkiye, ya, şekilde de batı lâiklik telâkkisine uyacak; Diyanet İşleri Reisliğini de dinî cemaate terkedecek, ya da, espride lâik telâkkiye sadık kalıp, şekilde ondan ayrılacak bir miktar... Mukayeseli tetkik bakımından, bir demokrasi gereği, "şu șekil zarurîdir, öteki zarurî değildir» diyemez.

Mukayeseli devlet tetkiklerinin bulacağı genel trend'ler yanında, o memleketin özelliğinden doğan özel trendleri de, yine mukayeseli tetkikler meydana çıkarabilir. Meselâ, ordunun, siyasete aktif olarak katılması, devletin gelişmesinde bir rolü olması meselesinde, Türkiye'nin durumunu en iyi olarak yine bir mukayeseli tetkik ile tebarüz ettirebiliriz. Ordunun, Türkiye'de de, önce tarihinde bir sosyal önderlik yaptığını; Lâtin Amerika'da ordunun bir kültür unsuru olmamasina mukabil, Osmanlılarda, ordunun kültürel bir siyasi vazife yerine getirdiğini; Osmanlılarda, düșünce tarzının değişmelerinin, ordudan başladığını, modernist ve lâik düşüncenin ordudan geldiğini; ama, meselâ, diğer memleketlere - meselâ Arap memleketlerine- kıyasla, Türkiye'de, ordunun gördüğ̈̈ önderlik görevinin, bütün hareketlerin, generallerle, onun yakın subay ve genç subaylar elinde geliștiğini, oysa ki, diğer memleketlerde - meselâ Arap memleketlerinde- ilk askerî siyasî hareketlerin, generallerden değil, mülâzimlenden, teğmenlerden geldiğini de, bize, anoak mukayeseli bir tetkik verebilir.

3 - Mukayeseli devlet tetkiklerinin başlama ve genişleme konusunda da, Dr. Rustow'un açiklamalarına ek olarak \$su noktalar belirmiştir: Türlï milletleri ve onların siyasi toplumlarını, modern mukayeseli devlet tetkiklerinden önce, türlü șarkiyat enstitüleri incelerdi. Bu enstitülelr, Asya-Afrika memeketlerini, tarih, edebiyat, kültür bakımlarından, ele alırdı. Sonradan duyulan pratik ihtiyaçlandır ki, bu millet ve toplumlara ait siyasi müesseseleri de incelemeği zorunlu kılmıștır. Batı dünyası; bu memleketleri, tarihi, edebiyatları, kültürleri ile beraber, siyasi müesseseleri ile de anlayıp, onlara karşı akıllı davranma yollarını bulımak istemiştir. $\mathrm{Bu}$ maksatla, önce Amerika'da, şarkiyat üzerine ihtisas yapmış olanları Washington'a getirtip, müitehassıs olarak kullanmışlardır. Fakat, siyasi hâdiseyi kavramada, bu şarkiyatçıların yardımından, bazı mahzurlar da çıkmıștır. Bu yüzden, siyasi hâdiseler üzerine müitehassıslar meydana çıkarma yoluna gidildi. Yalnız, siyasî 
müesseseler üzerinde ihtisas yapanlar, kültür konularında da bir temele dayanmak ihtiyacı ile, o memleketlerin kültür hayatlarını da inceliyorlar.

Mukayeseli devlet tetkileri içine, Güney Amerika devletleri de girmiştir. Bunlar, daha çok, Afrika - Asya grupua dahil imişler gibi, yeni bir etuid konusu teşkil etmektedirler.

Rusya, üçte biri ile Asya'da mevout olmasına rağmen, onun üzerinde müstakil çalışmalar vardır.

Bütün bunlara rağmen, mukayeseli devlet tetkiklerinin \%80 i, genel olarak, Ingiltere, Fransa, Almanya üzerinde cereyan etmiştir. 935 - 940 senelerinden sonradir ki, bu genel büyük paya, Rusya da ilâve edilmiştir. 